\title{
Numerical Simulation of a Cylindrical Heat Pipe and Performance Study
}

\author{
Mohammed Noorul Hussain, Isam Janajreh * \\ Masdar Institute of Science and Technology, Abu Dhabi, UAE
}

\begin{abstract}
Heat Pipes are passive devices used for transferring heat from a heat source to a heat sink with very small difference in temperature. They have three main sections namely the evaporator, adiabatic section and the condenser. In construction terms, they have three parts, the metal container, the porous wick region which lines the container from inside and the hollow flow chamber. Heat pipe performance is governed by several parameters such as the geometry, dimensions, working fluid, wick and container materials etc. In this study numerical simulation method was used to analyze the performance of the heat pipe. A numerical model based on Navier stokes equation, Energy equation and conjugate heat transfer was developed using COMSOL Multiphysics package. The top wall temperature profile obtained was validated with experimental results, and further the absolute thermal resistance was calculated. A sensitivity study was carried out to study the performance dependency of heat pipe on four parameters namely, porosity, condenser evaporator lengths, radius of heat pipe and the heat input, in terms of the absolute thermal resistance. The results showed that absolute thermal resistance varied directly with respect to porosity of the wick, and inversely in case of radius of the heat pipe. The absolute thermal resistance was maximum in case of equal condenser and evaporator lengths. Interestingly the absolute thermal resistance did not vary with the applied heat rate, demonstrating the practicality in using absolute thermal resistance as a performance characteristic parameter.
\end{abstract}

Keywords: Heat pipe performance, Absolute thermal resistance, Numerical simulation, Experimental validation.

\section{Introduction}

Working of a heat pipe is simple but the complexity lies in the physics that govern this process. It is closed tube, whose inner walls are lined up with a capillary structure or wick. A certain amount of thermodynamic fluid is always present in the chamber. When heat is applied to the heat pipe at the evaporator section, the fluid vaporizes in the section, by absorbing the latent heat and then the difference in vapor pressure drives the fluid to the condenser section. The heat sink is at the condenser section cools the vapor and condenses it to liquid, where the liquid releases its latent heat acquired during evaporation to the heat sink. This liquid is then absorbed by the porous wick and transported back to the evaporator by capillary action. This process continues as long as there is enough capillary pressure [1]. It is this wicking structure that makes the heat pipe different from a thermo-syphon. This allows the heat

${ }^{*}$ Corresponding author. Tel.: +971 28109130

Fax: +9876543210; E-mail: Author.ijanajreh@masdar.ac.ae

(C) 2016 International Association for Sharing Knowledge and Sustainability

DOI: $10.5383 /$ ijtee. 12.02 .010 pipe to work independent of gravity force in horizontal and angular configurations. Heat pipes are used in several places. They have a strong application in electronic devices, where they are used for cooling devices like workstation, laptops, compact electronic equipment etc. In cold places like Alaska heat pipes are used for maintaining stability of the permafrost under the Trans- Alaskan pipeline system [2]. Some other major applications include aerospace, thermal energy storage systems, heat exchangers, gas turbines, production, human body temperature control, manufacturing, etc. The performance of heat pipe as already mentioned is governed by several factors, such as geometry, materials, and properties. Depending on the application and suitability the shape oval, cylindrical or rectangular shape is selected [3]. Faghri [4] in 1991 carried out experiments to analyze the frozen startup of low and high temperature, cylindrical circumferentially heated, copper-water heat pipes. At the evaporator an electric circumferential heater with a maximum heat input of $250 \mathrm{~W}$ 
was used. At the condenser section a chilled water supply was used to provide the necessary heat sink. The heat pipe was instrumented with 14 outer wall and 6 vapor centerline thermocouples. Initially a step wise heat input method was adopted, but later a stable power of $100 \mathrm{~W}$ was preferred. Janajreh et al [5] worked on building a numerical model of a cylindrical heat pipe using Ansys fluent software. They concentrated on simulating the pressure drop in the vapor region and obtaining the velocity profile. Pooyoo et al [6] also worked on developing a model in fluent to obtain the pressure conditions and velocity profile in the vapor and liquid regions. However they used the SIMPLEC code and employed a nonDarcian approach for the wick region, using the Brinkman equation for flow in porous media for the liquid flow in the porous wick. Taoufik et al [7] studied the working of a cylindrical heat pipe under critical and steady state conditions i.e. at very high heat flux, using a FORTRAN code and considering a three dimensional Navier- Stokes and DarcyBrinkman- Forchheimer equations. They compared their results with previously done 2-D study, and achieved good agreement with those results. It can be inferred from their study that although 3-Dimensional analysis would be more accurate, 2-dimensional analysis can be preferred for most industrial and academic purposes. Min et al [8] experimented with a heat pipe having 2 different condenser sections, one cooled by natural convection and having annular fins, and the second cooled by a liquid in forced convection scenario. The evaporator was subjected to a maximum heat input of $1 \mathrm{KW}$. They reported nearly twenty times higher thermal conductivity at $270^{\circ} \mathrm{C}$ as compared to what a normal copper pipe would provide. Still much work is needed to gain better understanding of the performance of the heat pipe.

In this work numerical model based on Navier stokes equation, Energy equation and conjugate heat transfer was developed using COMSOL Multiphysics package. A sensitivity study was conducted to study the performance dependency of heat pipe on four parameters namely, porosity, condenser evaporator lengths, radius of heat pipe and the heat input, in terms of the absolute thermal resistance.

\section{Methodology}

To measure the heat pipe performance it is very important to achieve the top wall temperature profile. Considering a cylindrical heat pipe, a 2D axi-symmetric model was constructed. The dimensions of the heat pipe were as per the actual as shown in Fig. 1. Copper is the containing material, and water is the working fluid. A sintered copper mesh was considered as wick. Main aim was to achieve the top wall temperature profile, calculate the absolute thermal resistance, then perform the sensitivity study. In COMSOL multi-physics the modules used were 'heat transfer in solids' for wick and copper wall and 'heat transfer in fluids' for vapor region. A physics controlled mesh was selected which had 9 variations from extremely coarse to extremely fine. A Fine mesh with 42832 domain elements and 5459 boundary elements was employed.

To simplify the analysis a single phase steady state approach was adopted, where in only vapor flow was considered in the hollow chamber and only liquid flow considered in the wick region. Laminar flow was assumed for the vapor and Darcy's law was applied to the liquid flowing in the wick. The saturation temperature of water was considered as $349.15 \mathrm{~K}$. The rate of heat being added at the evaporator was considered to be equal to the rate of heat being rejected at the condenser.

The governing equation considered for the vapor flow is the Navier- Stokes equation for momentum conservation, which is given in Eq. 1 and in cylindrical co-ordinates $r, \theta$, and $z$.

$\rho(u . \nabla) u=\nabla\left[-p . I+\mu\left(\nabla u+(\nabla u)^{T}\right)\right]$

The energy balance equation is given in Eq. 2 .

$$
\rho C_{p} \nabla T=\nabla(k(\nabla T)+Q
$$

The first term represents the derivative in axial direction. The second term is the gradient of temperature in radial co-ordinate $r$, and the third term accounts for the internal volumetric heat generation. This energy equation is applied for all the three sections i.e. vapor, liquid and the solid copper container. For the flow in liquid- wick region Darcy's law was applied which is given in Eq. 3 and 4.

$\nabla(\rho . u)=Q_{m}$

$u=-\frac{k}{\mu} \nabla p$

Where $\mathrm{Q}_{\mathrm{m}}$ is a mass source term, which is zero in this case and $\mathrm{k}$ is the permeability of the porous wick.

\subsection{Boundary Conditions}

The boundary conditions applied adhere to the assumptions made and reflect the working conditions of the heat pipe. Fig. 2 shows the boundary conditions.

966

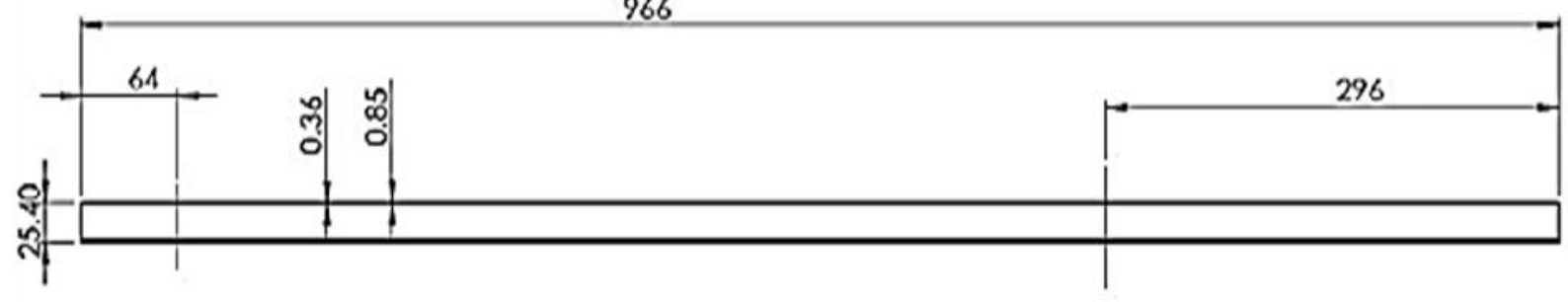

Fig. 1. Dimensions of the considered heat pipe (in mm) 


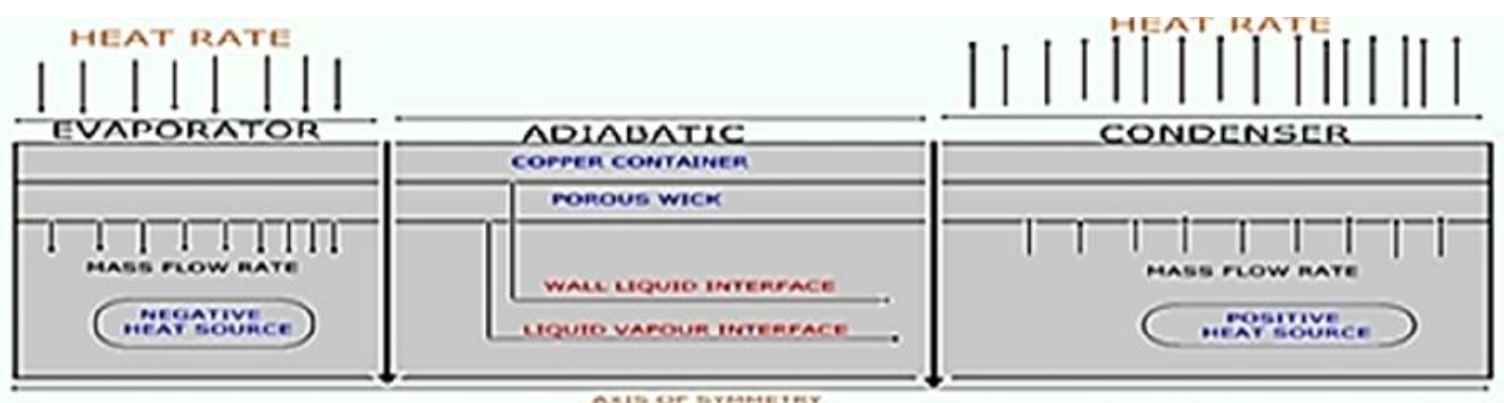

Fig. 2. Boundary conditions

At the outer surfaces of the heat pipe the following boundary conditions were applied:

$$
\begin{aligned}
& \frac{\partial T_{\text {solid }}}{\partial r}=+\frac{Q}{2 \pi R_{\text {oUT }} L_{e}} \\
& \frac{\partial T_{\text {solid }}}{\partial r}=0 \\
& \frac{\partial T_{\text {solid }}}{\partial r}=-\frac{Q}{2 \pi R_{\text {oUT }} L_{c}}
\end{aligned}
$$

Eq. 5 pertains to the boundary condition at the evaporator wall, Eq. 6 for the adiabatic section wall and Eq. 7 for the condenser wall. At both ends of the pipe Eq. 8 was considered.

$$
\frac{\partial T_{\text {solid }}}{\partial z}=0 \quad \frac{\partial T_{\text {liquid }}}{\partial z}=0
$$

A temperature boundary condition was considered for all the walls in the vapor regions, since the vapor is considered to be at an isothermal condition of saturation temperature, as shown in Eq. 9.

$$
T=T_{\text {sat }}
$$

Since single phase analysis of the working fluid was considered, it is necessary to compensate for the latent heat absorption and release at the evaporator and condenser, failing which the analysis is irrelevant. Therefore, a positive volumetric heat generating source term representing latent heat release is considered in the condenser chamber and a negative volumetric heat generation source term is considered in the evaporator region, which are given in Eq. 10, 11.

$$
\begin{aligned}
& s_{e}=-\frac{Q}{\pi\left(\left(R_{\text {Int }}+t\right)^{2}-R_{\text {Int }}^{2}\right) L_{e}} \\
& s_{c}=-\frac{Q}{\pi\left(\left(R_{\text {Int }}+t\right)^{2}-R_{\text {Int }}^{2}\right) L_{C}}
\end{aligned}
$$

For the flow in the vapor region, from a mass balance equation the inlet and exit flow conditions were defined in terms of mass flow rates. Mass flow rate was calculated using the enthalpy equation for latent heat at inlet and exit.

$Q=\dot{m} \mathrm{~h}_{f g}=\rho_{\mathrm{v}} \mathrm{A} \vee \mathrm{h}_{\mathrm{fg}}$

$v_{i e}=+\frac{Q}{2 \pi R_{i} \cdot L_{e} \rho_{v} h_{f g}}$

$v_{i c}=+\frac{Q}{2 \pi R_{i} \cdot L_{c} \rho_{v} h_{f g}}$

The boundary conditions for the walls in terms of flow were;

$\mathrm{u}=\mathrm{v}=0$

These boundary conditions were as per the earlier works of Shoeib and Ali [9]. The thermal conductivity of the wick, which is a porous layer depends on the conductivity of liquid $\left(\mathrm{k}_{\mathrm{L}}\right)$ flowing through it, the material of the wick $\left(\mathrm{k}_{\mathrm{w}}\right)$ and the porosity (ع), and is as given in Eq. 15 considering the wick is of isotropic porosity.

$$
\frac{k_{L}\left[\left(k_{L}+k_{w}\right)-(1-\varepsilon)\left(k_{L}-k_{w}\right)\right]}{\left(k_{L}+k_{w}\right)+(1-\varepsilon)\left(k_{L}-k_{w}\right)}
$$

The absolute thermal resistance which is the temperature difference in a structure when unit heat energy flows through it in unit time was calculated according to Eq. 16.

$R_{t h}=\frac{T_{\text {eva } a v g}-T_{c o n, a v g}}{Q_{i n}}$

\subsection{Properties and Input Parameters}

For the evaporator and condenser an inward and outward heat rate of $100 \mathrm{~W}$ was considered, since this is an approximation to what occurs in some electronic equipment [6]. Using which all other parameters were calculated. Table 1 . Shows all the input parameters considered for the analysis. The thermal and material properties were considered as per Table 2 .

No such term was considered for the adiabatic section. 
Table. 1 Input Parameters

\begin{tabular}{lll}
\hline Condition & Value & Units \\
\hline Evaporator heat rate & 100 & $\mathrm{~W}$ \\
Condenser heat rate & -100 & $\mathrm{~W}$ \\
Inlet mass flow rate vapor & $1.78 \mathrm{E}-05$ & $\mathrm{~kg} / \mathrm{s}$ \\
Outlet mass flow rate vapor & $1.78 \mathrm{E}-05$ & $\mathrm{~kg} / \mathrm{s}$ \\
Heat source at evaporator & $\mathrm{W}$ & -100 \\
Heat source at condenser & $\mathrm{W}$ & 100 \\
\hline
\end{tabular}

Table. 2 Thermal Properties of Materials

\begin{tabular}{lll}
\hline Description & Units & Value \\
\hline Saturation temperature & $\mathrm{K}$ & 349.15 \\
Latent heat & $\mathrm{J} / \mathrm{kg}$ & 2341000 \\
Vapor density & $\mathrm{kg} / \mathrm{m}^{3}$ & 0.258 \\
Vapor dynamic viscosity & $\mathrm{Pa} . \mathrm{s}$ & 0.000011 \\
Specific heat for vapor & $\mathrm{J} / \mathrm{kg} . \mathrm{K}$ & 1942 \\
Thermal conductivity of vapor & $\mathrm{W} / \mathrm{mK}$ & 0.0261 \\
Liquid density & $\mathrm{kg} / \mathrm{m}^{3}$ & 975 \\
Liquid dynamic viscosity & $\mathrm{Pa} . \mathrm{s}$ & 0.00037 \\
Specific heat for liquid & $\mathrm{J} / \mathrm{kg} . \mathrm{K}$ & 4186 \\
Liquid thermal conductivity & $\mathrm{W} / \mathrm{m} . \mathrm{K}$ & 0.58 \\
Effective wick conductivity & $\mathrm{W} / \mathrm{m} . \mathrm{K}$ & 1.2 \\
\hline
\end{tabular}

\section{Results and Discussion}

Upon model completion, a fully coupled, non-linear solver approach was employed. This finite element solver couples all the determined physics and solves the problem in a comprehensive method. It applies Newton-Rhapson iterations to the initial guess until the solution converges. Convergence is achieved when the relative error between 2 successive iterations is of the prescribed order of tolerance. In this case all solutions converged with an error of the order $10^{-4}$, considering which the solution is judged reliable

\subsection{Experimental Validation}

The top wall temperature profile, with respect to the heat pipe length, achieved is shown in Fig. 3. It was validated by comparing it with experimental results obtained by Faghri et al [4]. It is noticed that the temperature profile at the adiabatic region is a straight line for the numerical simulation, whereas for experimental results it is not the case. This could be because in actual practice there is some heat exchange taking place in the adiabatic section. However since the discrepancies are small one can continue to assume the central section is adiabatic. The solid contour of velocity magnitude obtained for the vapor region is shown in Fig. 4. The maximum velocity of $0.45 \mathrm{~m} / \mathrm{s}$ occurs in the adiabatic section, since the pressure difference between the evaporator section and the condenser section drives the flow through the adiabatic section.

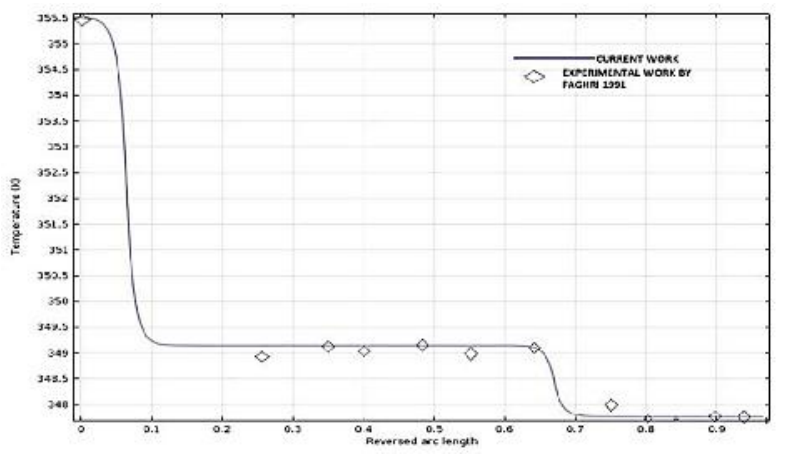

Fig. 3 Top wall temperature profile at porosity 0.7

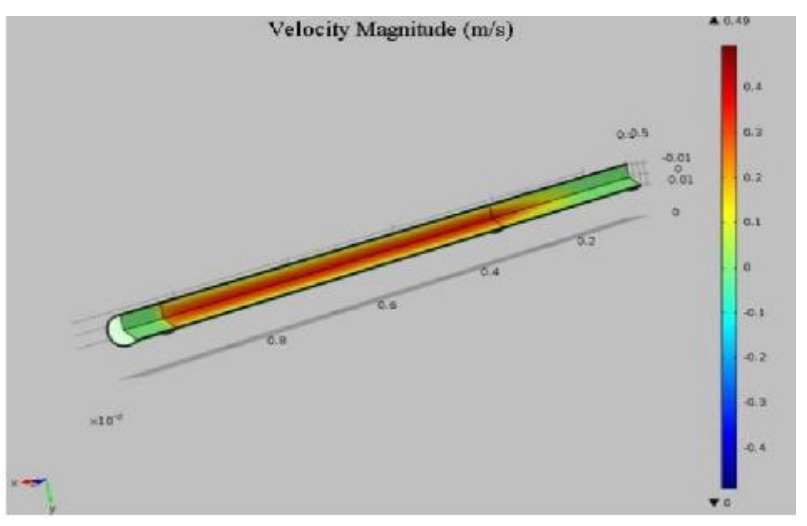

Fig. 4 Velocity profile at 0.7 porosity

\subsection{Sensitivity Study}

For designing or selecting a heat pipe, the dependency of its performance on crucial parameters has to be assessed. This will decide the suitability of the heat pipe for the application which it is being considered. It will also help in designing the heat pipe to match the requirement. Assessment of heat pipe is done by calculating the absolute thermal resistance as given in Eq. 16. This method is common and has been used in some previous studies [8]. Performance is considered good for a heat pipe when the absolute thermal resistance is as low as possible. In this work, the performance dependency of the heat pipe on wick porosity, evaporator and condenser length, internal radius and inward heat flux was considered.

\subsection{Effect of Porosity}

Three porosities, $0.3,0.5$, and 0.7 were considered for this study. Table 3 shows the variation in effective conductivity of the wick region with change in porosity. It was noticed that with increasing porosity there was an increase in thermal resistance. Fig 5 shows the wall temperature profiles for three different porosities. Fig 6 shows the variation in thermal resistance versus the porosity.

Table 3 Variation of thermal conductivity of wick

\begin{tabular}{|c|c|c|c|}
\hline $\begin{array}{c}\text { Liquid } \\
\text { thermal } \\
\text { conductivity } \\
\mathrm{W} / \mathrm{mK}\end{array}$ & $\begin{array}{c}\text { Wick } \\
\text { Thermal } \\
\text { Conductivity } \\
\mathrm{W} / \mathrm{mK}\end{array}$ & Porosity & $\begin{array}{c}\text { Effective } \\
\text { Thermal } \\
\text { conductivity } \\
\mathrm{W} / \mathrm{mK}\end{array}$ \\
\hline 0.58 & 385 & 0.7 & 1.075 \\
\hline 0.58 & 385 & 0.5 & 1.733 \\
\hline 0.58 & 385 & 0.3 & 3.259 \\
\hline
\end{tabular}




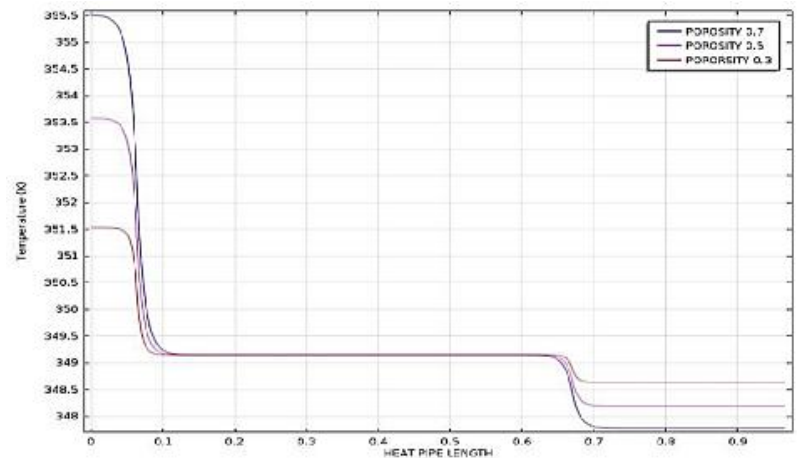

Fig. 5 Wall temperature profile at 3 porosities

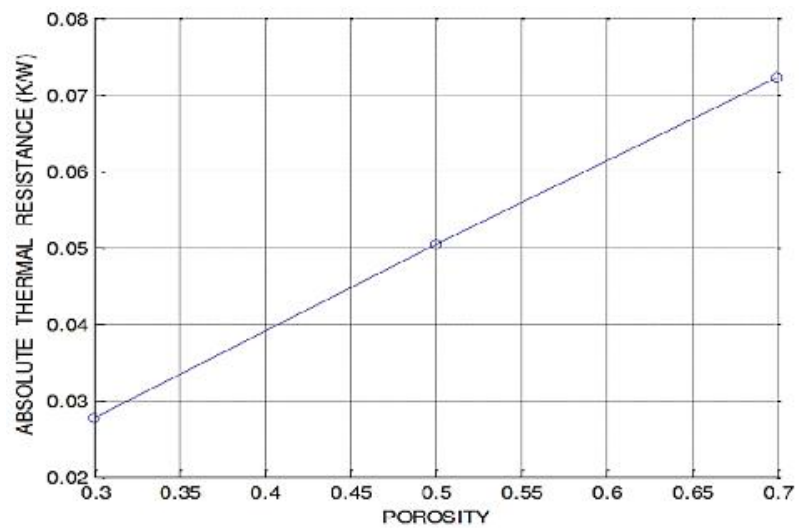

Fig. 6 Variation of thermal resistance with porosity

With increase in porosity the effective thermal conductivity of the liquid-wick layer decreases, thereby decreasing the heat transfer which means reduced thermal conductivity. With high porosity there is less copper in the sintered wick, hence resistance increases.

\subsection{Effect of Condenser and Evaporator Lengths}

In some applications there are constraints related to spacing of the heat pipe which effects the evaporator and condenser lengths. This can have a positive or a negative effect on the thermal resistance of the heat pipe. In this work, a parametric study was conducted considering 3 cases. Firstly the evaporator was considered longer than the condenser, second case was with equal evaporator and condenser lengths and the third case was with condenser longer than evaporator. The porosity was fixed at 0.7 . Fig. 7 shows the temperature profile for the three cases and Fig. 8 shows the effect on thermal resistance, which is plotted on x-axis. From the results it is inferred that there is not much difference between the 2 cases of unequal evaporator and condenser lengths, but the resistance in case of equal lengths is substantially high.

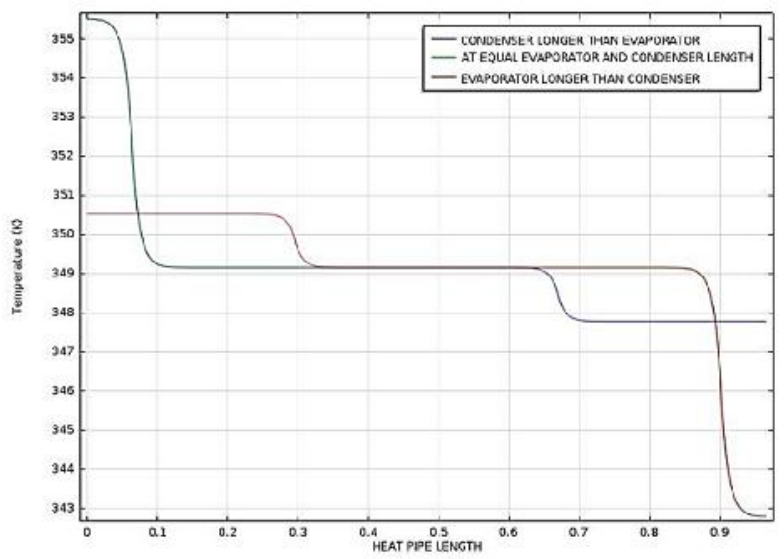

Fig. 7 Top wall temperature profile for 3 cases. Porosity 0.7

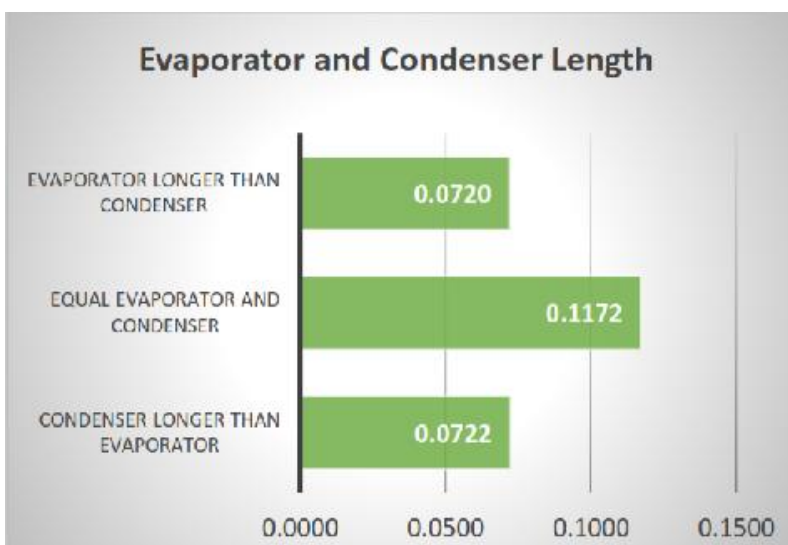

Fig. 8 Absolute thermal resistance for 3 cases at 0.7 porosity

\subsection{Effect of Internal Radius:}

For this part of the study, the internal radius was varied by increasing $2 \mathrm{~mm}$ and reducing $2 \mathrm{~mm}$ and then plotting the resultant thermal resistances. Fig. 9 shows the wall temperature profiles and Fig. 10 shows the resistance plot. With increase in the internal radius the thermal resistance decreased. This is highly practical, and can be validated by the mere reference to the Fourier's law of conduction, which states that the thermal conductivity is directly proportional to the cross section area. Hence by increasing the internal radius we increase the cross section area thereby increasing the conductance in-turn reducing the resistance. However it should be noted that an optimum radius has to be selected such that there is no effect on the vapor flow. 


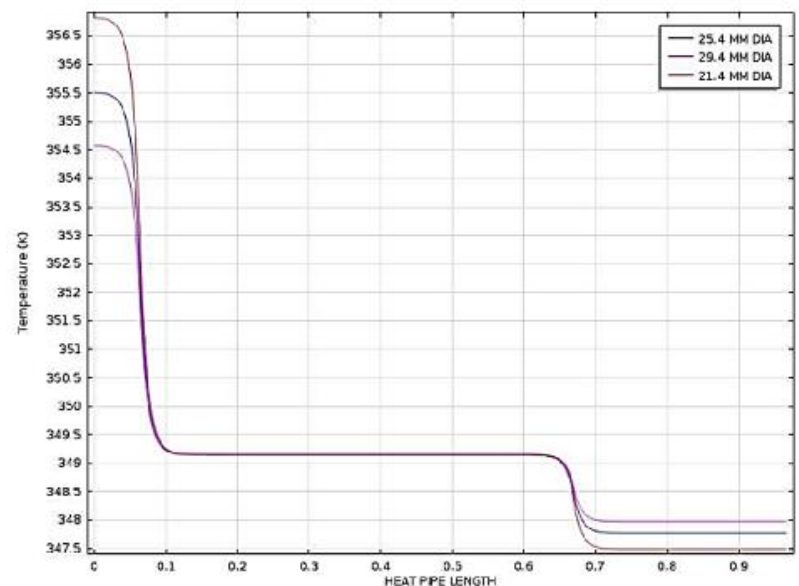

Fig. 9 Wall temperature profile at 3 different radii, porosity 0.7

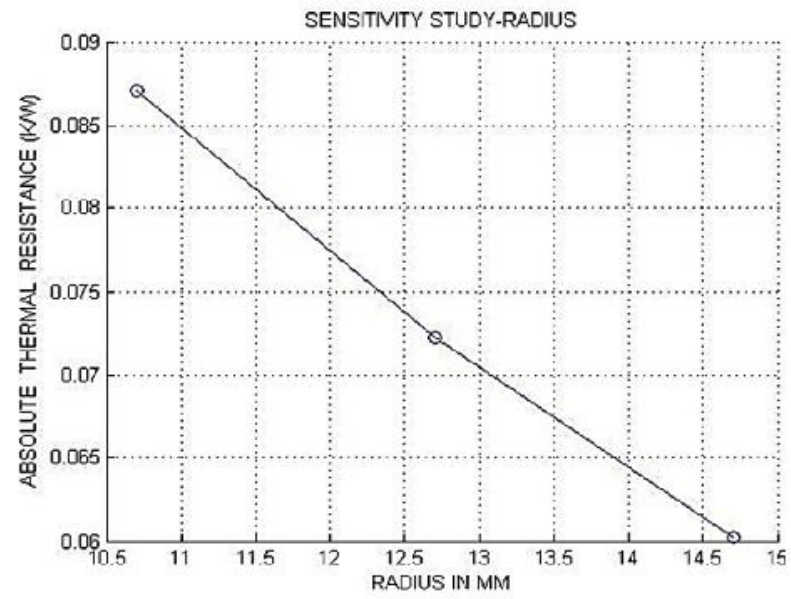

Fig. 10 Thermal resistance variation with radii, porosity 0.7

\subsection{Effect of Input Heat Rate}

To check thermal performance of the heat pipe at different heat input rates, applied heat rate was varied as $50 \mathrm{~W}, 100 \mathrm{~W}$ and 200 $\mathrm{W}$. Interestingly results showed the variation in thermal resistance did not change significantly. The maximum difference was of the order 0.01 . This shows the insensitivity of the heat pipe to the input rate and determines the practicality in using absolute thermal resistance as the judging factor for the performance of the heat pipe. The wall temperature profiles and resistance plots are shown in Fig. 11 and 12 respectively.

Table 4 summarizes the differences in average temperatures of evaporator and condenser which were used to calculate the absolute thermal resistance.

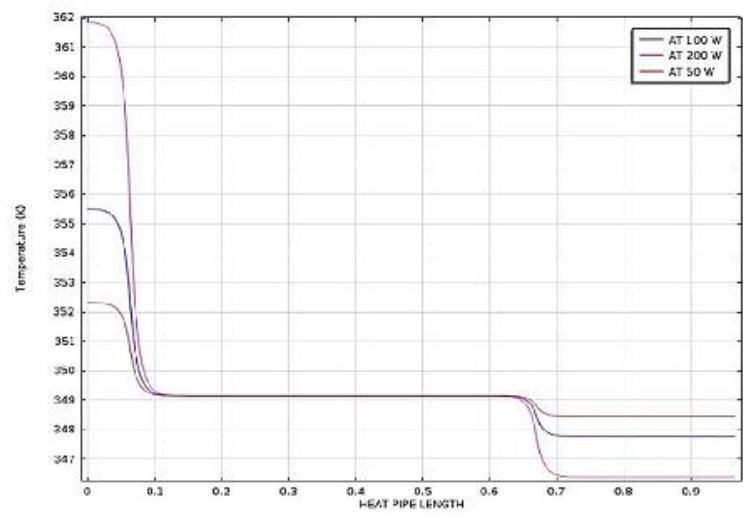

Fig. 11 Wall temperature profile at 3 different heat rates, porosity 0.7

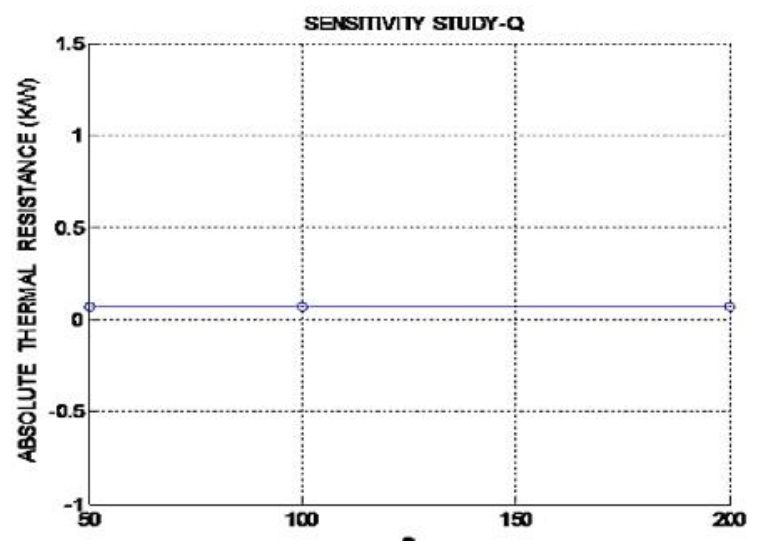

Fig. 12 Variation of thermal resistance with heat rate, porosity 0.7

\section{Conclusion}

In this work, a 2D axi-symmetric numerical model of a cylindrical heat pipe was successfully made using COMSOL Multi-physics software. A single phase steady state approach was used to achieve the top wall temperature profile and thereby calculate the absolute thermal resistance of the heat pipe. The temperature profile was validated with earlier done experimental works. Then a sensitivity study to check dependency of the heat pipe performance in terms of absolute thermal resistance on porosity, evaporator-condenser lengths, internal radius and applied heat was performed. The result of this analysis showed that with increase in porosity the absolute thermal resistance also increased, due to the decrease in conductivity of the liquid-wick region. In the second case, the absolute thermal resistance was highest for when the evaporator and condenser lengths were equal. Thirdly the resistance decreased with increase in internal radius, which is a result of heat transfer due to increase in cross section area. Lastly, heat rate change did not affect the thermal resistance proving the practicality in considering absolute thermal resistance as a performance characteristic parameter. However the assumption of single phase flow must be replaced by actual two phase transition based modelling to get better and accurate results. Also the model does not account for some effects and limits such as the viscous force of the vapor on the liquid, the boiling and entrainment limits etc. Nevertheless the model is considerably reliable with the applied simplifications, when ideal operating conditions are presumed. 
Table 4 Calculations of Absolute thermal resistance

\begin{tabular}{|c|c|c|c|c|c|}
\hline Parameter & Case & $\begin{array}{c}\mathbf{T} \text {-avg-Evaporator } \\
\mathbf{K}\end{array}$ & $\begin{array}{c}\text { T-avg- Condenser } \\
\mathbf{K}\end{array}$ & Difference & $\mathbf{R}_{\text {th }}(\mathbf{K} / \mathbf{W})$ \\
\hline \multirow{3}{*}{ Porosity } & 0.7 & 355.02 & 347.8 & 7.22 & 0.0722 \\
\hline & 0.5 & 353.25 & $348.2 \mathrm{~L}$ & 5.04 & 0.0504 \\
\hline & 0.3 & 351.42 & 348.65 & 2.77 & 0.0277 \\
\hline \multirow{3}{*}{$\begin{array}{l}\text { Evaporator and condenser } \\
\text { Lengths at } 0.7 \text { porosity }\end{array}$} & Condenser longer than & 355.02 & 347.8 & 7.22 & 0.0722 \\
\hline & $\begin{array}{c}\text { evaporator } \\
\text { Equal evaporator and } \\
\text { condenser }\end{array}$ & 355.02 & 343.3 & 11.72 & 0.1172 \\
\hline & $\begin{array}{c}\text { Evaporator longer than } \\
\text { condenser }\end{array}$ & 350.5 & 343.3 & 7.2 & 0.0720 \\
\hline \multirow{3}{*}{ Radii at 0.7 porosity } & $10.7 \mathrm{~mm}$ & 356.23 & 347.52 & 8.71 & 0.0871 \\
\hline & $12.7 \mathrm{~mm}$ & 355.02 & 347.8 & 7.22 & 0.0722 \\
\hline & $14.7 \mathrm{~mm}$ & 354.16 & 348 & 6.16 & 0.0616 \\
\hline \multirow{3}{*}{$\begin{array}{l}\text { Varying input heat at } 0.7 \\
\text { porosity }\end{array}$} & $100 \mathrm{w}$ & 355.02 & 347.8 & 7.22 & 0.0722 \\
\hline & $200 \mathrm{w}$ & 360.87 & 346.45 & 14.42 & 0.0721 \\
\hline & $50 \mathrm{w}$ & 352.07 & 348.47 & 3.6 & 0.0720 \\
\hline
\end{tabular}

Nomenclature

\begin{tabular}{ll}
\hline Symbol & Description \\
\hline $\mathrm{P}$ & Density \\
$\mathrm{U}$ & Velocity \\
$\mathrm{P}$ & Pressure \\
$\mathrm{M}$ & Dynamic Viscosity \\
$\mathrm{T}$ & Temperature \\
$\mathrm{C}_{\mathrm{p}}$ & Specific heat \\
$\mathrm{k}$ & Thermal conductivity \\
$\mathrm{k}$ & Permeability \\
$\mathrm{Q}$ & Heat rate, $\mathrm{W}$ \\
$\mathrm{r}$ & radial co-ordinate \\
$\mathrm{Z}$ & Axial co-ordinate \\
$\Theta$ & Angular co-ordinate \\
$\mathrm{L}_{\mathrm{e}}$ & Length of Evaporator \\
$\mathrm{L}_{\mathrm{c}}$ & Length of condenser \\
$\mathrm{R}_{\mathrm{th}}$ & Absolute thermal resistance \\
$\mathrm{V}$ & velocity \\
$\mathrm{S}_{\mathrm{e}, \mathrm{c}}$ & Source terms \\
$\mathrm{R}_{\mathrm{int}}$ & Internal radius \\
$\mathrm{t}$ & thickness of wick \\
$\mathrm{h}_{\mathrm{fg}}$ & Latent heat of vaporization \\
$\mathrm{k}_{\mathrm{l}}$ & Conductivity of liquid \\
$\mathrm{k}_{\mathrm{w}}$ & conductivity of wick \\
$\mathrm{R}_{\mathrm{out}}$ & Outer radius \\
$\mathrm{E}$ & Wick porosity \\
\hline &
\end{tabular}

\section{References}

[1] A. F Mills., Heat Transfer, $2^{\text {nd }}$ ed., 1991, Prentice Hall, Upper Saddle River, New Jersey, USA, Chap 7, pp 730 -744 .

[2] M. Sarah, Permafrost vol-1, 8th Int. Conference on Permafrost, Zürich. 2003, ISBN 9058095827.

[3] P. D. Dunn., D.A Reay., Heat Pipes, Theory Design and Applications, 2005, Pergamon, New York.

[4] A. Faghri., Analysis of frozen startup of high temperature heat pipes and three dimensional modeling, Interim Report for Period January 1990-May 1991, Aero Propulsion and Power directorate, Wright Laboratory 1991,.

[5] N. Z. Ahmed., K. S. Pawan., I. Janajreh, and Y. Shatilla, "Simulation of flow inside heat pipe: sensitivity study, conditions and configuration". Proceedings of the $5^{\text {th }}$ International conference on energy Sustainability $\& 9^{\text {th }}$ Fuel cell science, engineering and technology conference, 2011 Washington DC, USA.

[6] N. Pooyoo., S. Kumar., J. Charoensuk., and A. Suksangpanomrung., "Numerical simulation of cylindrical heat pipe considering non-Darcian transport for liquid flow inside wick and mass flow rate at liquidvapor interface". International Journal of Heat and Mass Transfer, 2014, 70, pp 965 - 978.

[7] B. Taoufik., and J. Abdelmajid., "Heat Pipe simulation under critical conditions". Frontiers in Heat Pipes, 2012, 3.

[8] K. P. Min., and H. B. Joon., "Thermal Performance of a Heat Pipe for Medium-Temperature thermal Storage System". 10 $0^{\text {th }}$ International Heat Pipe Symposium, 2011, Taipei, Taiwan.

[9] M. Shoeib., and M. Ali., "Numerical Simulation of a Conventional Heat Pipe". International Scholarly and Scientific Research \& Innovation, 2008, 2 (3). 